This is an electronic reprint of the original article. This reprint may differ from the original in pagination and typographic detail.

\author{
Author(s): Torppa, Minna; Georgiou, George K.; Lerkkanen, Marja-Kristiina; Niemi, Pekka; \\ Poikkeus, Anna-Maija; Nurmi, Jari-Erik
}

Title: $\quad$ Examining the Simple View of Reading in a Transparent Orthography: A Longitudinal Study From Kindergarten to Grade 3

Year: $\quad 2016$

Version:

Please cite the original version:

Torppa, M., Georgiou, G. K., Lerkkanen, M.-K., Niemi, P., Poikkeus, A.-M., \& Nurmi, J.E. (2016). Examining the Simple View of Reading in a Transparent Orthography: A Longitudinal Study From Kindergarten to Grade 3. Merrill-Palmer Quarterly, 62(2), 179-206. https://doi.org/10.13110/merrpalmquar1982.62.2.0179

All material supplied via JYX is protected by copyright and other intellectual property rights, and duplication or sale of all or part of any of the repository collections is not permitted, except that material may be duplicated by you for your research use or educational purposes in electronic or print form. You must obtain permission for any other use. Electronic or print copies may not be offered, whether for sale or otherwise to anyone who is not an authorised user. 


\title{
Examining the Simple View of Reading in a Transparent Orthography: A Longitudinal Study From Kindergarten to Grade 3
}

\author{
Minna Torppa University of Jyväskylä \\ George K. Georgiou University of Alberta \\ Marja-Kristiina Lerkkanen University of Jyväskylä \\ Pekka Niemi University of Turku \\ Anna-Maija Poikkeus and Jari-Erik Nurmi University of Jyväskylä
}

This study examined the dynamic relationships among the components of the Simple View of Reading (SVR) in a transparent orthography (Finnish) and the predictive value of cognitive skills (phonological awareness, letter knowledge, rapid naming, and vocabulary) on the SVR components. Altogether, 1,815 Finnish children were followed from kindergarten to Grade 3 . Their cognitive skills were assessed in kindergarten, listening comprehension and reading fluency in Grades 1 and 2, and reading comprehension in Grades 1-3. Reading fluency and listening comprehension accounted for $37 \%$ of the variance in reading comprehension in Grade 2 and $28 \%$ in Grade 3. The direct effect of reading fluency on reading comprehension disappeared after Grade 1, whereas the effect of listening comprehension remained significant across time. Cognitive skills predicted reading comprehension mainly indirectly via listening comprehension and reading fluency in Grade 1. These findings support the validity of the SVR model in the context of a transparent orthography, but they also show that the direct effect of reading fluency on reading comprehension wanes after the early school years.

Minna Torppa, Marja-Kristiina Lerkkanen and Anna-Maija Poikkeus, Department of Teacher Education; George K. Georgiou, Department of Educational Psychology; and Pekka Niemi and Jari-Erik Nurmi, Department of Psychology.

This study has been carried out in the Centre of Excellence in Learning and Motivation Research financed by the Academy of Finland (No. 213486 for 2006-2011) and other grants from same funding agency for the project (No. 268586 for 2013-2017) and to Minna Torppa (No. 276239 for 2014-2018).

Address correspondence to Minna Torppa, PO Box 35, University of Jyväskylä, F-40014 Jyväskylä, Finland. Phone: +(358) 408053538. E-mail: minna.p.torppa@jyu.fi.

Merrill-Palmer Quarterly, April 2016, Vol. 62, No. 2, pp. 179-206. Copyright (C 2016 by Wayne State University Press, Detroit, MI 48201. 
Becoming a skilled reader who can decode and comprehend written language is an important prerequisite for full participation in the modern society. Better understanding of the building blocks of reading comprehension and how their contribution may change across time is needed for provision of evidence-based support for children and youth who struggle with tasks requiring comprehension of texts and written media. An influential theoretical account on reading, the Simple View of Reading (SVR; Gough \& Tunmer, 1986), suggests that reading comprehension is the product of efficient decoding ability and linguistic comprehension. Since its conception, the SVR model has received considerable empirical support (for reviews, see Kirby \& Savage, 2008; Stuart, Stainthorp, \& Snowling, 2008) and has had a major influence on reading research and practice. There is, however, a need for longitudinal examinations of the SVR model in transparent orthographies (Florit \& Cain, 2011). The present study examines SVR by using a longitudinal data set that spans from kindergarten to Grade 3 in Finnish, a language considered one of the most transparent orthographies among the alphabetic languages in Europe (Seymour, Aro, \& Erskine, 2003). In addition to the examination of the validity of SVR in Finnish, the current study seeks to extend previous studies by including preliteracy skills (phonological awareness, letter knowledge, rapid naming, and vocabulary) as predictors of the SVR components.

The empirical evidence in support of SVR comes from at least five sources. First, the combination of decoding and linguistic comprehension has been found to account for a significant amount of variance in reading comprehension, mainly in English, but also in other orthographies, including Dutch (de Jong \& van der Leij, 2002), Finnish (Dufva, Niemi, \& Voeten, 2001), Greek (Kendeou, Papadopoulos, \& Kotzapoulou, 2013), French (Megherbi, Seigneuric, \& Ehrlich, 2006), and Turkish (Babayiğit \& Stainthorp, 2011). Second, although decoding and reading comprehension correlate, factor analytic approaches have demonstrated that decoding and linguistic comprehension load on separate factors and thus form distinct constructs (e.g., Kendeou et al., 2013; Kendeou, Savage, \& van den Broek, 2009). Third, intervention studies have shown that gains in decoding skills do not always translate into gains in reading comprehension (e.g., Edmonds et al., 2009). Fourth, there are children who experience difficulties in reading comprehension despite adequate decoding, as well as children who have developed average reading comprehension despite difficulties in decoding (e.g., Cain, Oakhill, \& Bryant, 2004; Catts, Adlof, \& Weismer, 2006; Catts, Hogan, \& Adlof, 2005; Nation, Clarke, Marshall, \& Durand, 2004; Stothard \& Hulme, 1995; Torppa, Tolvanen, et al., 2007). Finally, reports from behavioral genetic studies suggest that decoding and 
comprehension are influenced by partially independent genetic components (e.g., Betjemann et al., 2008; Harlaar et al., 2010; Keenan, Betjemann, Wadsworth, DeFries, \& Olson, 2006; Olson et al., 2011).

Despite an accumulated body of work on SVR, longitudinal studies on the developmental relationships between the components of SVR are still scarce, particularly in languages other than English. The results of a meta-analysis covering a wide range of orthographies suggested that the predictive value of decoding and linguistic comprehension in reading comprehension might differ across languages varying in orthographic consistency (Florit \& Cain, 2011). To ascertain whether the SVR model developed for English is also valid in more transparent orthographies (e.g., Finnish), more research is warranted (see Florit \& Cain, 2011; Kendeou et al., 2013).

The SVR model was originally developed for explaining the proximal causes of individual differences in reading comprehension in English. In studies testing the SVR model, decoding is typically operationalized by measures of the accuracy of word and nonword reading. Gough and Tunmer (1986) defined decoding as the ability to "read isolated words, quickly, accurately, and silently" (p. 7), which suggests, however, that the measures of decoding should also include timed measures of word recognition to capture the development of automaticity in word recognition. The findings of studies with different operationalization of the decoding component (accuracy vs. fluency) suggest that the mechanism linking reading accuracy to reading comprehension may differ from the mechanism linking reading fluency to reading comprehension. While the link between exceedingly erroneous reading and difficulties in reading comprehension is quite obvious and straightforward, the link between low reading fluency and poor comprehension skills has been explained in terms of the memory constraints imposed on individuals (e.g., Cain et al., 2004; Georgiou, Das, \& Hayward, 2009) and limited cognitive resources (e.g., Perfetti, 1985). For a slow reader who may forget the beginning of the sentence before reaching its end, verbal memory can seriously constrain reading comprehension. In addition, according to the verbal-efficiency theory (Perfetti, 1985), reading fluency abets reading comprehension because automaticity in decoding frees up resources that can then be allocated to comprehension.

Several studies in English have examined the contribution of reading fluency with respect to the SVR-model assumptions (e.g., Adlof, Catts, \& Little, 2006; Georgiou et al., 2009; Hudson, Torgesen, Lane, \& Turner, 2012; Kim, Wagner, \& Foster, 2011; Kim, Wagner, \& Lopez, 2012; Klauda \& Guthrie, 2008; Silverman, Speece, Harring, \& Ritchey, 2013) but have provided mixed findings. For example, in a study with children in Grades 
2, 4, and 8, Adlof et al. (2006) found that reading fluency did not add to the prediction of reading comprehension when the effects of reading accuracy were controlled for. In contrast, Georgiou et al. (2009) showed that, in a group of poor readers in Grades 3 and 4, reading fluency did account for unique variance in reading comprehension over and beyond reading accuracy.

Because of the fast learning curve in reading accuracy, the examination of SVR in a transparent orthography gives an interesting point of departure to discuss the role of reading fluency. In the context of the Finnish language, reading accuracy hits a ceiling quite soon after the formal reading instruction begins (e.g., Aro \& Wimmer, 2003; Seymour et al., 2003), and, by the time reading comprehension can be reliably assessed, reading fluency is a more sensitive measure of decoding than is accuracy. Thus, in a transparent orthography like Finnish, the variability in reading fluency depends less on the variability in reading accuracy, and its effect on reading comprehension can be estimated already in the early grades. In their meta-analysis, Florit and Cain (2011) concluded that, in transparent orthographies, the effect of listening comprehension on reading comprehension appears to be stronger than that of decoding among beginning readers, whereas decoding has a strong influence on reading comprehension in English, even in the upper grades. However, they emphasized that longitudinal research on SVR in transparent orthographies is needed. It should also be noted that, in Florit and Cain's meta-analysis, every language other than English was included in the consistent orthography group. This kind of dichotomous classification is problematic because, along the transparency continuum, French or Dutch, among other languages, are not nearly as transparent as Finnish, Greek, Italian, or Spanish (Seymour et al., 2003). In this orthographic transparency continuum, Finnish lies at the opposite end of English, thus providing a strong testing ground for the effect of orthography in SVR.

Previous studies on SVR conducted in highly transparent orthographies (Finnish, Greek, Italian, and Spanish) are rare. The literature on SVR among children contains some studies in Greek (Diakidoy, Stylianou, Karefilliou, \& Papageorgiou, 2005; Kendeou et al., 2013; Protopapas, Simos, Siderisis, \& Mouzaki, 2012), Spanish (Calet, Defior, \& GutierrezPalma, 2015; Joshi, Tao, Aaron, \& Quiroz, 2013), and Italian (e.g., Roch \& Levorato, 2009), but these were all cross-sectional. Three previous studies have analyzed SVR components in the context of Finnish-namely, studies by Lerkkanen, Rasku-Puttonen, Aunola, and Nurmi (2004), Müller and Brady (2001), and Dufva et al. (2001). Their findings suggest that listening comprehension is a strong predictor of reading comprehension in Finnish 
already in the early grades. However, there are methodological limitations in each of these studies. The Müller and Brady study was cross-sectional. The study by Lerkkanen et al. cannot be interpreted as directly testing the assumptions of the SVR because kindergarten predictors of the development of reading comprehension and fluency were analyzed separately (or as a combined reading-performance measure) during Grades 1 and 2 and the links were not estimated in a joint model. Furthermore, neither Müller and Brady, nor Lerkkanen et al. controlled for classroom effects, and they used observed instead of latent variables (thus including measurement error in their models). The design of the study by Dufva et al. did not allow controlling for autoregressors because it did not contain several assessments of the SVR components. None of the SVR studies controlled for the effects of classroom membership.

Some evidence is available on SVR from longitudinal studies in Dutch, which is a more transparent orthography than English but less transparent than Finnish. In the study by de Jong and van der Leij (2002), both reading fluency and listening comprehension in Grade 1 predicted reading comprehension in Grade 3, even after Grade 1 reading comprehension was controlled. Verhoeven and van Leeuwe (2008) controlled for the autoregressive effects in a Dutch longitudinal study with yearly assessments of vocabulary, listening comprehension, and reading fluency in Grades 1-6 and of reading comprehension in Grades 2-6. They showed that reading fluency and oral language measures (listening comprehension and vocabulary) were significant predictors of reading comprehension, with listening comprehension having stronger effects. They also found a reciprocal relationship between reading comprehension and oral language measures, but similar reciprocal relationships did not emerge between decoding fluency and reading comprehension. However, the measures used in Verhoeven and van Leeuwe's study for listening comprehension (and vocabulary after Grade 3) may have tapped reading skills, as well. Their tasks required students to answer multiple-choice questions in a booklet; therefore, the predictive power of the oral language measures may be partly due to the common reading-skill variance.

In addition to the SVR components, we examined the effects of kindergarten cognitive predictors of the SVR components: letter knowledge, phonological awareness, rapid naming, and vocabulary. A plethora of empirical evidence documents the contribution of these early emerging skills to reading acquisition across languages (e.g., Caravolas et al., 2012; Georgiou, Parrila, \& Papadopoulos, 2008; Lonigan, Burgess, \& Anthony, 2000; Muter, Hulme, Snowling, \& Stevenson, 2004; Puolakanaho et al., 2007; Schatschneider, Fletcher, Francis, Carlson, \& Foorman, 2004). 
The link of letter knowledge and phonological awareness to reading development is straightforward; problems in the ability to process speech sounds (e.g., identify phonemes within words) or letters hinder the development of basic decoding that requires mapping speech sounds to letters (making sequences of grapheme-phoneme connections). Rapid naming, on the other hand, is more closely linked to reading fluency than to decoding (e.g., Georgiou et al., 2008; Puolakanaho et al., 2007; Savage \& Frederickson, 2005; Torppa, Georgiou, Salmi, Eklund, \& Lyytinen, 2012). Rapid naming tasks require rapid sequential naming of familiar items, thus being analogous with fluent reading. In addition to listening comprehension, early vocabulary has been shown to be a good predictor of reading development, particularly of reading comprehension (e.g., Cain et al., 2004; Manolitsis, Georgiou, \& Parrila, 2011; Nation et al., 2004; Ouellette, 2006; Ricketts, Nation, \& Bishop, 2007; Sénéchal, 2006; Torppa, Tolvanen, et al., 2007). It remains unclear, however, whether prereading skills affect reading comprehension directly or indirectly via decoding and listening comprehension. Direct links of the cognitive predictors to reading comprehension over and above reading fluency and listening comprehension would suggest that SVR needs expansion. Of particular interest is the role of vocabulary because it has been suggested to be a stronger language component in SVR than is listening comprehension (e.g., Ouellette \& Beers, 2010).

\section{The Present Study}

The purpose of our study was twofold: (a) to examine the validity of the SVR model in a highly transparent orthography (Finnish) by modeling the developmental dynamics of the components of SVR, and (b) to examine the effects of kindergarten cognitive predictors on the SVR model components. Specifically, we aimed to answer the following questions:

1. What are the longitudinal relationships between listening comprehension, reading fluency, and reading comprehension in Grades 1-3?

2. To what extent do preschool-age cognitive skills (letter knowledge, phonological awareness, rapid naming, and vocabulary) predict reading in Grades 1-3?

Our study makes four important contributions to the literature. First, it responds to the call for evidence on the applicability of SVR in the context of a transparent orthography. Second, this is among the few studies to examine the developmental dynamics between listening comprehension, reading 
fluency, and reading comprehension by using a longitudinal design that spans the first 3 years of school. Unlike most previous studies, we included autoregressors of each component, which enabled us to examine direct, indirect, and reciprocal/cross-lagged effects across time. In addition, whenever possible, we used latent factors instead of observed variables (thus reducing measurement error). Third, we included analyses utilizing kindergarten predictors of the SVR components. Finally, we were able to rely on a large data set with a nested data structure (children nested in classrooms) allowing us to estimate how much of the variance in children's skills can be attributed to being a member of a classroom and to correct the model estimates (standard errors) by taking into account to the nested data structure.

\section{Method}

\section{Participants and Procedure}

The present study is part of an extensive longitudinal study (Lerkkanen, Niemi, et al., 2006) in which a community sample of Finnish children was followed up from kindergarten (6 years) to Grade 4 (11 years) to investigate the development of academic skills and motivation, their associations with teacher and parent beliefs and practices, and classroom structural and process factors. Participants were recruited from three medium-sized towns and one municipality, two in Central, one in Western, and one in Eastern Finland. At the beginning of the study, the children's parents and teachers were asked for written consent. Of the parents who were contacted, $78 \%-89 \%$, depending on town or municipality, agreed to take part in the study. The sample was comparable to the general population in terms of parental educational level (Statistics Finland, 2007): 6\% had only the 9-year compulsory education ( $6 \%$ in the general population), $30 \%$ had completed a secondary education (30\% in the general population), 36\% had a bachelor's degree or vocational college degree (35\% in the general population), and $28 \%$ had a master's degree or higher (29\% in the general population).

The children participating in the present study $(n=1,815 ; 884$ girls and 931 boys) were a subsample of a larger project with about 2,000 children participating each year $(N=1,880$ in kindergarten, $N=2,008$ in Grade 1, $N=2,056$, in Grade 2, and $N=1,995$ in Grade 3). The sample size of the larger project changed somewhat each year due to factors such as shifts in teaching groups or absences during the testing days. There were children from 103 schools and 171 classrooms in Grade 1, 80 schools and 188 classrooms in Grade 2, and 77 schools and 193 classrooms in Grade 3 in the larger project. In the present study, we selected only those children 
who attended typical public Finnish classrooms and who had data on all assessments of reading comprehension $(n=1,815)$. The data on reading fluency, listening comprehension, and reading comprehension for these children in Grades 1-3 are almost complete, with none of the measures having more than $1.5 \%$ missing data. Of these children, 1,546 also participated in the kindergarten assessments. At the beginning of the study (kindergarten spring), the mean age of the children in the sample was 74.0 months ( $S D=3.48$ months). Kindergarten education is optional in Finland, and families whose children did not attend kindergarten were enrolled at school entry. In Grades 1-3, the number of participants in the assessments was larger $(n=1,815)$ than in kindergarten. The reading development of the children with and without data in kindergarten was compared and found similar, except for reading fluency in Grade 2, in which the mean score for children without kindergarten data was 23.4 words as opposed to 24.7 words for children with kindergarten data, $F(1,1813)=7.76, p<.01$. We used data from the spring assessments in kindergarten (April 2007), Grade 1 (April 2008), Grade 2 (April 2009), and Grade 3 (April 2010).

In Finland, compulsory education begins in the year of the child's seventh birthday. Approximately 98\% of all 6-year-olds in Finland attend kindergarten education, which is provided in day-care centers and elementary schools. The goals of the kindergarten curriculum center on fostering the child's personal and social development more than formally teaching academic skills. However, children are read to and encouraged to play with letters, words, and numbers. Through these playful activities, about half of children learn to decode at least few words during the kindergarten year (Torppa et al., 2013). In the national Grade 1 curriculum, there are $7 \mathrm{hr}$ of literacy learning per week. In these hours, students focus on learning to decode syllables and words, and practice fluency and comprehension with ABC books. Since word-level decoding reaches a high level of accuracy for most Grade 1 students after only a few months of school, students' commitment and motivation for silent reading to improve their fluency and comprehension are supported daily from Grades 1 and 2 onward, soon after they have acquired the decoding skill. Student gains in reading are encouraged by the availability of high-interest texts at multiple levels and by giving students the freedom to choose reading materials. They are also given time to read what they choose, without evaluative measures.

\section{Measures}

Children's reading fluency, listening comprehension, and reading comprehension were assessed in Grades 1 and 2 with group tests administered by trained experimenters in the children's classrooms. Reading comprehension 
was also assessed in Grade 3. The trained testers were undergraduate students in education or psychology. In a 1-week period, they received $8 \mathrm{hr}$ of training and $3 \mathrm{hr}$ of practice. In the kindergarten spring (April), trained testers in individual test sessions assessed vocabulary, phonological awareness, rapid naming, and letter knowledge.

Reading fluency. Two group-administered tests were used to assess reading fluency: a word-reading fluency task and a word-chain task. The word-reading fluency task is a subtest of the nationally normed reading test battery (Lindeman, 2000). Each of the 80 items consisted of a picture with four phonologically similar words attached to it. The child silently read the four words and then drew a line connecting the picture with the word, semantically matching it. The words and pictures were easy, frequently used words familiar to very young children. For example, there was a picture of a bunny (рири in Finnish) and three distractors (the English word is in parenthesis): pipo (cap), рари (bean), and ари (help). Completing the test requires detailed fluent decoding. The score was the number of correct answers within a 2-min time limit. Because of the nature of this timed test, the score reflects both the child's fluency in reading the stimulus words and accuracy in making the correct choice among the alternatives. Lindeman (2000) reported the Kuder-Richardson reliability coefficient to be .97 in Grade 1 and .82 in Grade 2. Alternate-form reliability between forms A and B was .84. In our sample, the Pearson correlation coefficient between Grades 1 and 2 was .67. The word-chain task was a timed test with 10 rows of word chains comprising 4-6 words written together without a space in-between. The child silently read the words comprising the chains and, while reading them, indicated the word boundaries by drawing a division line in-between. The score was the number of correct responses (max. $=40)$ within the time limit $(1 \mathrm{~min} 25 \mathrm{~s}$ in Grades 1 and 2, and $1 \mathrm{~min}$ $20 \mathrm{~s}$ in Grade 3). In our sample, the Pearson correlation coefficient between Grades 1 and 2 was .52.

Listening comprehension. In Grade 1, a group-administered test developed at the Centre for Learning Research, University of Turku, was used to assess listening comprehension. A story with 130 words was read aloud twice to the children in the classroom setting. There were six multiplechoice questions based on the text. Pictures accompanied the questions (in four of the questions there were three choices, and in two questions there were four choices). Children selected a picture that would best fit the story. Two points were given for each correct answer $(\max .=12)$. In Grade 2, a group-administered test was adapted from a subtest of the nationally normed reading test battery (Lindeman, 2000). A story with 135 words was read aloud twice to the children in the classroom setting. The tester then read the questions and the four alternative responses. The children 
were asked to mark their answers on the form showing picture choices. There were eight questions and 1 point was given for each correct answer (max. = 8). The Kuder-Richardson reliability coefficients were .39 in Grade 1 and .45 in Grade 2.

Reading comprehension. A group-administered subtest of the nationally normed reading test battery (Lindeman, 2000) was used to assess reading comprehension. The children silently read a fiction story and then answered 11 multiple-choice questions and one question in which they had to arrange five statements in the correct sequence based on the information gathered from the text. The text contained 146 words in Grade 1, 114 in Grade 2, and 139 in Grade 3. The children received 1 point for each correct answer $(\max .=12)$. Each child completed the task at his or her own pace, but the maximum time allotted was $45 \mathrm{~min}$. Lindeman (2000) reported the Kuder-Richardson reliability coefficients to be .85 in Grade 1, .80 in Grade 2, and .75 in Grade 3. Criterion validity was assessed based on 1,500 students in each grade. The Grade 1 correlation was .52 between decoding and teacher grading of word-reading ability and .49-.57 between components of reading comprehension and teacher grading. The overall reading comprehension score correlated with teacher grading .54 in Grade 2 and .36 in Grade 3. However, reading comprehension has been found to correlate also with scores of a concurrent test of mathematical performance (Lerkkanen et al., 2004; Lerkkanen, Rasku-Puttonen, Aunola, \& Nurmi, 2005) and performance in verbal math problems (Vilenius-Tuohimaa, Aunola, \& Nurmi, 2008). These findings likely reflect the shared variance between general cognitive capacity and various types of common academic performance.

Phonological awareness. The initial phoneme identification test from the test battery (Lerkkanen, Poikkeus, \& Ketonen, 2006) was used to assess phonological awareness in kindergarten. The children viewed a row of four pictures of objects, which the experimenter named. The experimenter then asked, "At the beginning of which word do you hear the sound /?/", and the children had to point out the correct picture. All sounds were single phonemes. The children's score was the number of correct responses (max. $=10$ ). The Kuder-Richardson reliability coefficient was .76.

Vocabulary. A 30-item shortened version of the Peabody Picture Vocabulary Test-Revised (PPVT-R, Form L; Dunn \& Dunn, 1981) was used as a measure of receptive vocabulary in kindergarten. In PPVT, the children select the picture that correctly represents a spoken word from four alternatives. The items for the shortened version were selected based on the data from the full-scale administration of the PPVT-R in the Jyväskylä Longitudinal Study of Dyslexia (see Lyytinen et al., 2004). The children's 
scores were the number of correct responses. The Kuder-Richardson reliability coefficient was .61 .

Letter knowledge. The children named all 29 letters in the Finnish language in kindergarten, which were arranged randomly in three rows (Lerkkanen, Poikkeus, \& Ketonen, 2006). The children named the letters, one row at a time, while the other rows were covered. The score was the number of correctly named letters $(\max .=29)$. The Kuder-Richardson reliability coefficient in our sample was .94 .

Rapid automatized naming (RAN). RAN was assessed in kindergarten by using the standard procedure (Denckla \& Rudel, 1976) in which children are asked to name as fast as possible a series of five pictures of objects arranged in semirandom order in five rows of 10. A practice trial preceded the test to ensure that each child was familiar with the objects. The total time to name all stimuli served as the children's scores. Only a few errors occurred and for this reason they were not considered further. The split-half reliability coefficient in our sample was .80 .

\section{Data Analysis}

The analyses were performed using the Mplus statistical package (Version 6; Muthén \& Muthén, 1998-2009). We first conducted a structural equation modeling (SEM) that included measures of listening comprehension, reading fluency, and reading comprehension to examine the developmental associations of the SVR components (research Question 1). We first estimated a model including all SVR regression paths and examined modification indexes provided in Mplus in order to identify potential ways to improve the fit of the model to data. We then fitted a second model that included the kindergarten predictors to examine their predictive power on the SVR components (research Question 2). In Model 2, all statistically significant $(p<.05)$ paths from Grade 1 were retained. By multiplying the standardized estimates by themselves, one obtains the percentage of variance explained by each predictor.

Because the analysis involved both continuous and dichotomous variables, a robust weighted least squares (WLS) approach was used with the weighted least squares minimum variance (WLSMV) estimator. WLSMV is a recommended estimator for data that include skewed variables and when both categorical and continuous measures are employed (Muthén \& Muthén, 1998-2009). The goodness-of-fit measures of the estimated cross-lagged path models were evaluated according to the following four indicators: (a) chi-square test, (b) comparative fit index (CFI), (c) root mean square error of approximation (RMSEA), and (d) weighted root 
mean square residual (WRMR). CFI values above .95 indicate a good fit. RMSEA values below .06 suggest a good fit, values of .06-.08 indicate an acceptable fit, and values larger than .08 indicate a poor fit. WRMR values below. 90 indicate a good fit (Muthén \& Muthén, 1998-2009).

Because of the nested structure of the data set (children nested within classrooms), the intraclass correlations (ICCs) were calculated to estimate the effect of membership in a certain teaching group. In nested data like the present ones, the children's scores within each classroom are nonindependent observations because they share the same classroom (same class teacher). The ICC is the estimate of the proportion of the total score variance that is attributable to an individual's membership in a particular classroom. Note that the reasons for nonindependence may relate to characteristics of classroom or teaching, but they may also relate to nonrandom placement of children into classrooms. The estimation of the ICCs was based on being in the same teaching group across Grades 1-3. These children may have experienced changes, such as different teachers, but they all had the same changes across Grades 1-3. In Finland, it is typical for children to remain in the same teaching group during the primary grades until Grade 7, which was the case in our data set. Of our sample $(n=1,815)$, 1,731 children $(95 \%)$ had been together with at least one other classmate for the first three grades, 1,689 with at least five classmates (93\%), and $1,644(91 \%)$ with at least 10 classmates. The estimation of ICCs was based on the 1,731 children who had at least one same classmate through the first three grades.

The ICC multiplied by 100 is the percentage of the an individual's skill total variance that is explained by membership in a certain teaching group or classroom. The ICCs were significant for the Grade 1 measures of listening comprehension (.03), reading fluency (.09), and reading comprehension (.09); for the Grade 2 measures of listening comprehension (.08), reading fluency (.07), and reading comprehension (.12); and for Grade 3 reading comprehension (.09). Because of the significant ICCs, all standard errors in the SVR models were corrected accordingly with the COMPLEX option provided by Mplus. Another choice is to use multilevel modeling, but since the model included no between-level predictors, we decided to use COMPLEX, which computes estimated standard errors and a chi-square test of model fit taking into account nonindependence of observations due to cluster sampling. Note that in models calculated with COMPLEX the variance of classrooms is not removed (Figures 1 and 2). It is noteworthy that the ICCs for these skills are almost equal to those in other studies conducted in Finland, both 
in this sample (e.g., Ahtola et al., 2011) and in others (e.g., Torppa, Tolvanen, et al., 2007).

\section{Results}

\section{Preliminary Data Analysis}

First, we examined the distributional properties of the various measures in the study. All of the measures, means, standard deviations, minimum, and maximum values are reported in Table 1 . Grade 1 listening comprehension, letter knowledge, and phoneme identification were negatively skewed. Therefore, the correlation coefficients for these measures are reported as Spearman rho coefficients in Table 2. Five extremely slow values in RAN were winsorized to the last nonoutlier plus 1 . Note that RAN correlates negatively with the other measures because higher scores in RAN mean worse performance.

Table 1. Descriptive statistics of measures for kindergarten and Grades 1-3

\begin{tabular}{lrrrr}
\hline & $M$ & $S D$ & Min. & Max. \\
\hline Kindergarten & & & & \\
$\quad$ Vocabulary & 20.00 & 3.26 & 7 & 29 \\
$\quad$ Phoneme identification & 9.06 & 1.55 & 0 & 10 \\
$\quad$ Letter knowledge & 23.69 & 6.18 & 0 & 29 \\
$\quad$ Rapid naming(s) & 69.82 & 16.95 & 34 & 150 \\
Grade 1 & & & & \\
$\quad$ Reading comprehension & 5.63 & 3.14 & 0 & 12 \\
$\quad$ Word-reading fluency & 18.67 & 8.79 & 0 & 58 \\
$\quad$ Word chains & 7.11 & 5.09 & 0 & 32 \\
$\quad$ Listening comprehension & 10.05 & 1.80 & 0 & 12 \\
Grade 2 & & & & \\
$\quad$ Reading comprehension & 8.64 & 2.60 & 0 & 12 \\
$\quad$ Word-reading fluency & 24.50 & 7.50 & 3 & 58 \\
$\quad$ Word chains & 11.51 & 6.08 & 0 & 38 \\
$\quad$ Listening comprehension & 4.94 & 1.62 & 0 & 8 \\
Grade 3 & & & & \\
$\quad$ Reading comprehension & 9.19 & 2.07 & 0 & 12 \\
\hline
\end{tabular}




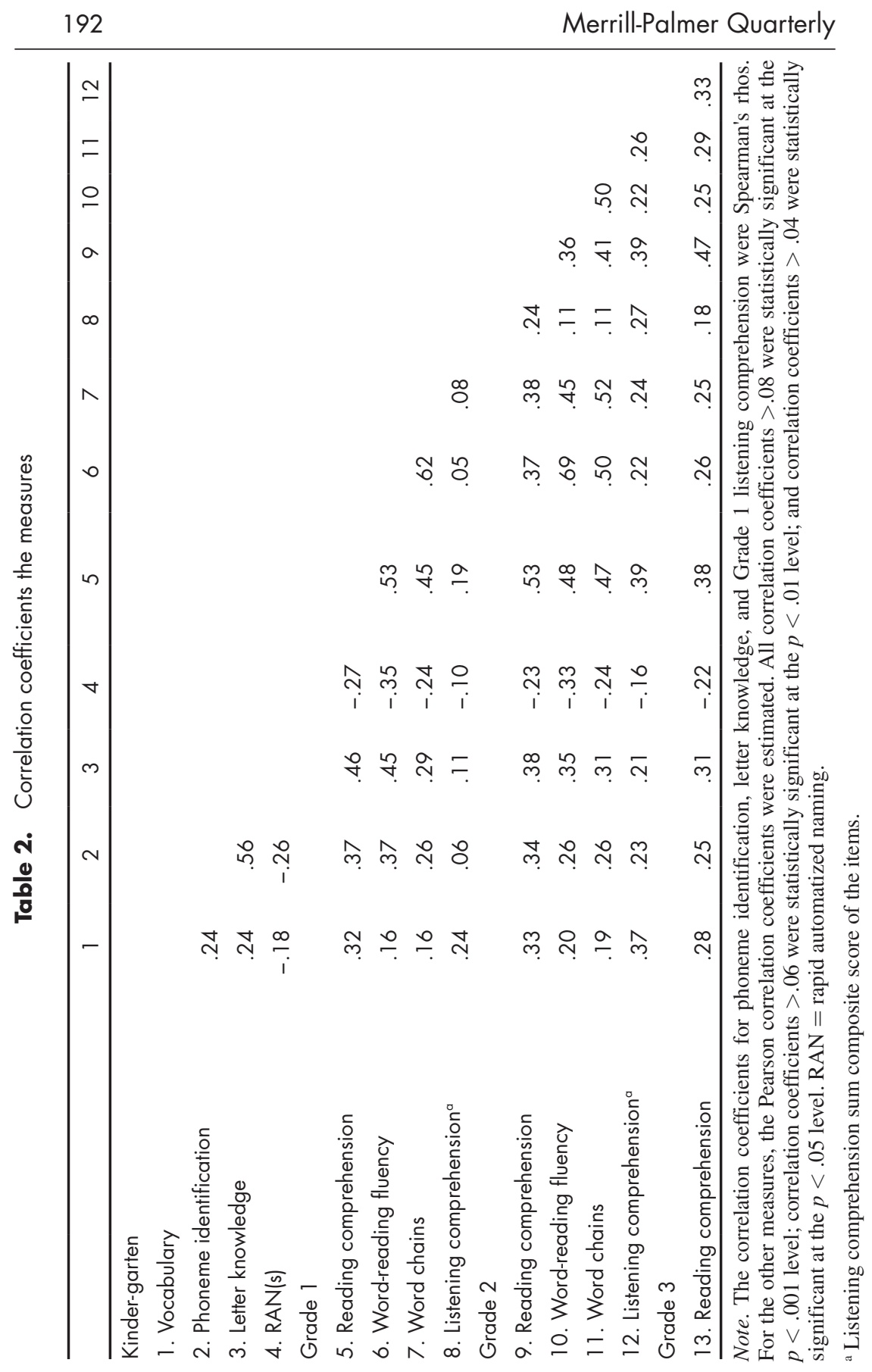


The Longitudinal Path Model for the Development of Listening Comprehension, Reading Fluency, and Reading Comprehension in Grades 1-3

To examine the developmental associations among listening comprehension, reading fluency, and reading comprehension, we estimated longitudinal path models (Figure 1). Latent factors were constructed for listening comprehension and reading fluency so as to reduce measurement error in the model. The listening comprehension factors consisted of the dichotomous items of the tasks (six items in Grade 1, and eight items in Grade 2), and the reading-fluency factors consisted of the two reading-fluency tasks

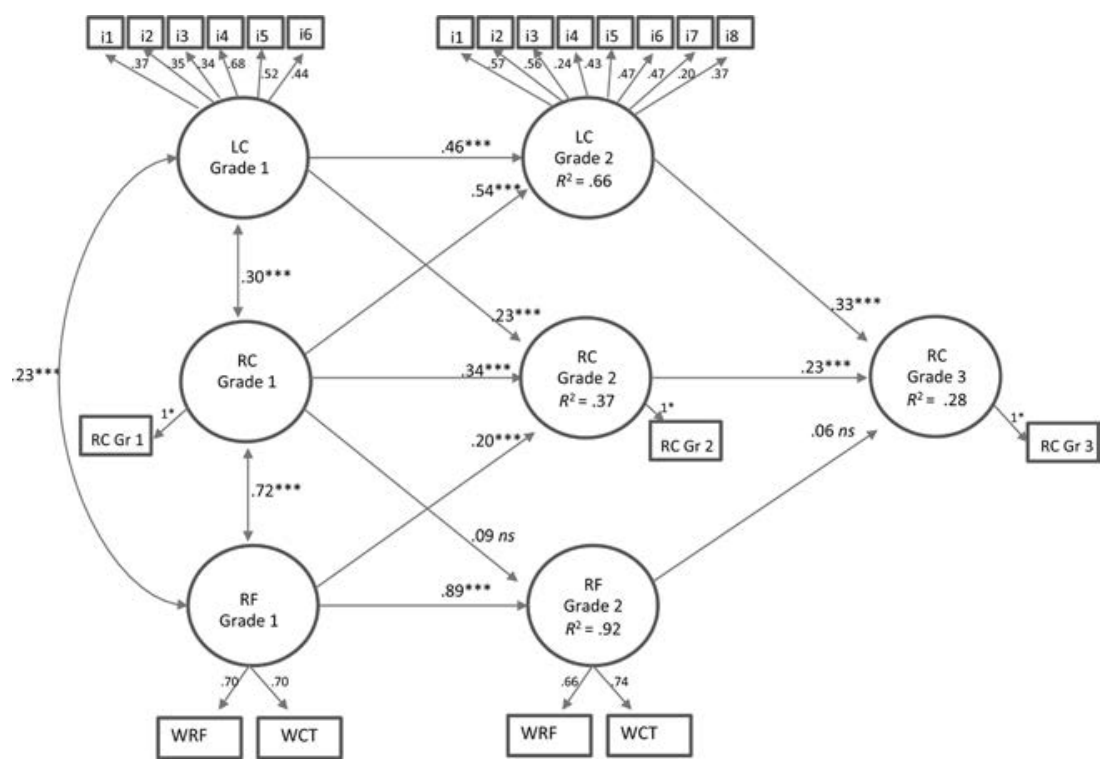

Figure 1. The standardized path estimates and $R^{2}$ values for the Simple View of Reading prediction model of reading comprehension in Grades 1-3: LC = listening comprehension; $\mathrm{RC}=$ reading comprehension; $\mathrm{RF}=$ reading fluency; $\mathrm{WRF}=$ wordreading fluency; $\mathrm{WCT}=$ word-chain test; $\mathrm{i}=$ item. In addition to the figure, five significant parameters were estimated in the model (standardized estimates in parentheses): the error covariance between word-reading fluency task in Grades 1 and 2 (.43), between reading comprehension and listening comprehension in Grade 2 (.26), between listening comprehension Items 6 and 7 in Grade 2 (.13), between listening comprehension Items 3 and 7 in Grade 2 (.26), and between listening comprehension Items 5 and 6 in Grade 1 (.26). 
(word-reading fluency and word chains). Reading comprehension was a single-indicator latent factor in this model, with the loading set to 1 . The model fit was good $\chi^{2}(174)=213.11, p=.02, \mathrm{CFI}=.99$, RMSEA $=.01$, $\mathrm{WRMR}=.85$. (See Figure 1 for the fully standardized coefficients.)

The longitudinal path model first revealed that listening comprehension and reading fluency were correlated with Grade 1 reading comprehension and with each other. The correlation between reading fluency and reading comprehension was strong (.72). Both reading fluency and listening comprehension predicted additional variance in Grade 2 reading comprehension over and above the Grade 1 autoregressor. However, their unique effects were small: The amounts of unique explained variances in Grade 2 reading comprehension were $4 \%$ for reading fluency and $5.3 \%$ for listening comprehension. The total amount of variance accounted for in reading comprehension in Grade 2 was 37\%. Reading comprehension in Grade 3 was significantly predicted by the Grade 2 listening comprehension and the autoregressor (Grade 1 reading comprehension) but not by the Grade 2 reading fluency. The total amount of variance accounted for in reading comprehension in Grade 3 was $28 \%$. The relationship between reading comprehension and listening comprehension was reciprocal. Reading comprehension predicted Grade 2 listening comprehension over and above Grade 1 listening comprehension. Of the Grade 2 listening comprehension variance, $66 \%$ was predicted by Grade 1 reading comprehension and the Grade 1 autoregressor. There were also small, but significant, indirect effects: Grade 1 reading fluency had an indirect effect on Grade 3 reading comprehension (standardized effect .06, $p<.001$, predicting $0.4 \%$ of the variance in Grade 3 reading comprehension), and Grade 1 listening comprehension had an indirect effect on Grade 3 reading comprehension (standardized effect .20, $p<.001$, predicting $4 \%$ of the variance in Grade 3 reading comprehension).

\section{Kindergarten Predictors of Reading Comprehension, Listening Comprehension, and Reading Fluency}

To answer our second research question, we estimated the SVR model, including the predictors from kindergarten; vocabulary, phoneme identification, rapid naming, and letter knowledge (Figure 2). The longitudinal model where all nonsignificant school-age path estimates are omitted but where all paths from kindergarten predictors are retainedsee Figure 2, $\chi^{2}(250)=344.80, p<.001$, CFI $=.98$, RMSEA $=.01$, 


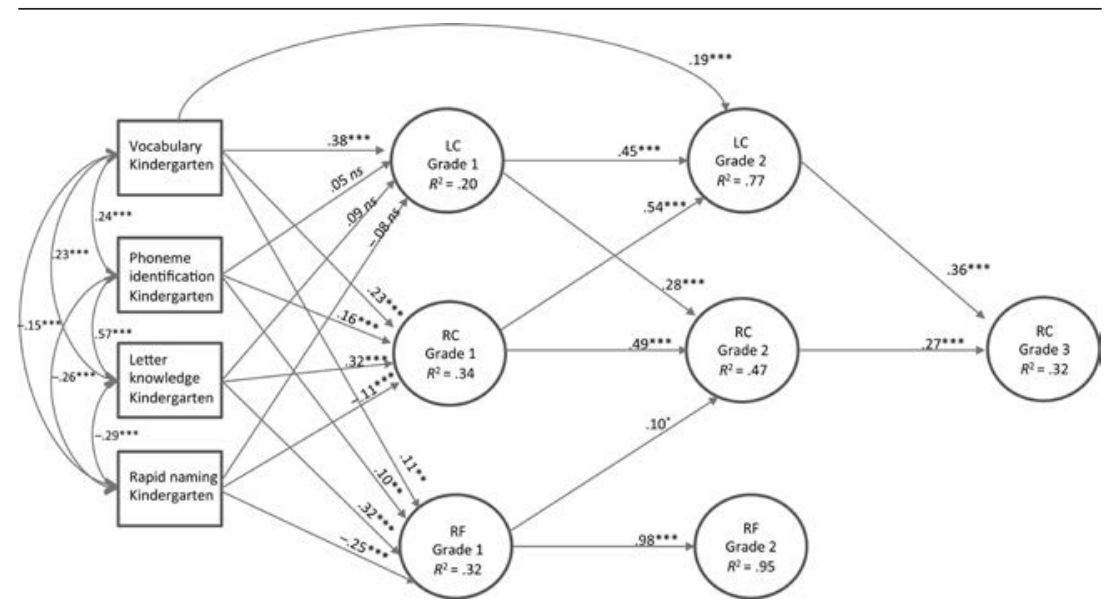

Figure 2. The standardized significant path estimates and $R^{2}$ values for the prediction model of reading comprehension with additional predictors from kindergarten: $\mathrm{LC}=$ listening comprehension; $\mathrm{RC}=$ reading comprehension; $\mathrm{RF}=$ reading fluency. In addition to the figure, three significant parameters were estimated in the model (standardized estimates in parentheses): the error covariance between wordreading fluency task in Grades 1 and 2 (.36), between listening comprehension Items 6 and 7 in Grade $2(.13)$, between listening comprehension Items 3 and 7 in Grade 2 (.26), and between listening comprehension Items 5 and 6 in Grade 1 (.25).

WRMR $=.94-$ accounted for $34 \%$ of the variance in Grade 1 reading comprehension, $47 \%$ of the variance in Grade 2 reading comprehension, $32 \%$ of the variance in Grade 3 reading comprehension, $20 \%$ of the variance in Grade 1 listening comprehension, 77\% of the variance in Grade 2 listening comprehension, $32 \%$ of the variance in Grade 1 reading fluency, and $95 \%$ of the variance in Grade 2 reading fluency. Vocabulary was the only significant kindergarten predictor of listening comprehension. Reading comprehension and reading fluency were predicted by all kindergarten skills. The strongest predictors of reading comprehension were letter knowledge and vocabulary, and the strongest predictors of reading fluency were letter knowledge and rapid naming. In addition to the direct effects on Grade 1 skills and Grade 2 listening comprehension, the kindergarten cognitive measures had small, but significant, indirect effects on Grade 2 skills and Grade 3 reading comprehension (see Table 3). Note that the interpretation of the indirect effects is same as for direct standardized path estimates. 
Table 3. The standardized estimates of the indirect effect of kindergarten measures on listening comprehension, reading fluency, and reading comprehension in Grades 2 and 3.

\begin{tabular}{lcccc}
\hline & Vocabulary & $\begin{array}{c}\text { Phoneme } \\
\text { identification }\end{array}$ & $\begin{array}{c}\text { Letter } \\
\text { knowledge }\end{array}$ & Rapid naming \\
\hline Reading comprehension & & & & \\
$\quad$ Grade 2 & $.22^{* * *}$ & $.10^{* * *}$ & $.22^{* * *}$ & $-.10^{* * *}$ \\
Grade 3 & $.23^{* * *}$ & $.07^{* * *}$ & $.14^{* * *}$ & $-.07^{* * *}$ \\
Listening comprehension, & & & & \\
Grade 2 & $.16^{* * *}$ & $.06^{* * *}$ & $.12^{* * *}$ & $-.05^{* * *}$ \\
Reading fluency, Grade 2 & $.08^{* * *}$ & $.07^{* * *}$ & $.22^{* * *}$ & $-.24^{* * *}$ \\
\hline${ }^{*} p<.05$. & & & & \\
${ }^{* *} p<.01$. & & & \\
${ }^{* * * *} p<.001$. & & &
\end{tabular}

\section{Discussion}

The aims of the present study were (a) to examine the validity of the SVR model in a highly transparent orthography (Finnish) by modeling the developmental dynamics of the components of SVR and (b) to examine the effects of kindergarten cognitive predictors on the SVR model components. The investigation responds to the evident need for and call by researchers for systematic and extended research on the developmental mechanisms and links between the antecedent skills leading to fluent reading comprehension, particularly in orthographies that are more transparent than English (Florit \& Cain, 2011; Kendeou et al., 2013). For the most part, the findings supported the assumed mechanisms of the SVR model, showing that both efficient decoding and linguistic comprehension are needed for reading comprehension; however, the findings also underlined how short-lived the explanatory power of reading fluency is in a highly transparent orthography. The analyses indicated a developmental shift from a strong relationship between reading comprehension and reading fluency in Grade 1 to a prediction only by listening comprehension. Reading fluency and listening comprehension were relatively weakly related as constructs. Second, our modeling showed that kindergarten-age cognitive skills predicted reading comprehension, but that their effect on reading comprehension after Grade 1 was mediated by listening comprehension and reading fluency.

The present findings are consistent with those of previous studies in transparent orthographies in that the effect of listening comprehension 
was strong compared to reading fluency (for a review, see Florit \& Cain, 2011; see also Dufva et al., 2001, and Verhoeven \& van Leeuwe, 2008). The model showed, however, that the link between reading comprehension and reading fluency is strong in Grade 1, but that further developmental changes in reading fluency from Grade 1 to Grade 2 spring are not linked to reading comprehension. However, had the model included a cross-sectional predictive path from Grade 1 reading fluency to Grade 1 reading comprehension, a stronger indirect effect would have emerged (the correlation was strong: $r=.72$ ). Because Finnish children obtain a sufficient level of decoding for comprehension very early on, the effect of reading fluency on reading comprehension diminishes early. Our findings reflect the fast early literacy acquisition phase in a transparent language context: Because of the high transparency of the Finnish orthography and systematic phonics teaching, the majority of children are accurate and also relatively fast readers after a year of formal reading instruction (e.g., Aro \& Wimmer, 2003; Holopainen, Ahonen, \& Lyytinen, 2001; Torppa et al., 2012). These findings support the prior conclusion that the contribution of decoding to reading comprehension is likely to decline quickly in highly transparent orthographies (e.g., Florit \& Cain, 2011). Our findings are also in line with the verbal-efficiency theory (Perfetti, 1985). In transparent orthographies, the strong predictive role of reading fluency in reading comprehension is expected to decrease earlier because early development of automaticity in decoding frees up resources for comprehension.

Our findings support those of Verhoeven and van Leeuwe (2008), who reported a developmental model of the SVR components in Dutch; that is, we also found that, over time, listening comprehension became a stronger predictor of reading comprehension than of reading fluency. In addition, in both our model and Verhoeven and van Leeuwe's model, reading comprehension predicted subsequent listening comprehension. However, the relative strengths of reading fluency and listening comprehension also differed as predictors of reading comprehension. In our analyses, reading fluency had a substantially stronger correlation with reading comprehension in Grade 1 than did listening comprehension, whereas the effects in Verhoeven and van Leeuwe's model were stronger for listening comprehension in Grade 1. This difference could be attributed to differences in the characteristics of Finnish and Dutch orthographies but may also relate to differences in how listening comprehension was measured. The measure used by Verhoeven and van Leeuwe required answering multiple-choice questions in a booklet, whereas the measure we used in this study did not require reading; rather, we used pictures to decrease children's memory loads. 
In terms of the cognitive predictors of the SVR components, our findings are consistent with an existing body of research showing that phonological awareness, rapid naming, and letter knowledge are robust predictors of decoding (e.g., Kirby, Parrila, \& Pfeiffer, 2003; Lerkkanen et al., 2004; Lonigan et al., 2000; Manolitsis, et al., 2011; Puolakanaho et al., 2007) and reading comprehension (e.g., Lepola et al., 2005; Torppa, Poikkeus, et al., 2007). However, their links to reading skills in Grades 2 and 3 were mediated by Grade 1 decoding and reading comprehension, which supports the validity of the SVR model in the Finnish language context. When these findings are taken together, they suggest that the children who manifest problems in antecedent phonological awareness, rapid naming, and letter knowledge are at highest risk for developing reading comprehension and fluency problems.

Vocabulary has also been shown to be a significant predictor of reading comprehension (e.g., Cain et al., 2004; Manolitsis et al., 2011; Nation et al., 2004; Ouellette, 2006; Ricketts, Nation, \& Bishop, 2007; Sénéchal, 2006; Torppa, Tolvanen, et al., 2007). In the present study, most of the contribution of vocabulary to reading comprehension was mediated by listening comprehension, which suggests that the variance in kindergarten vocabulary overlapped with that of listening comprehension in Grades 1 and 2. Ouellette and Beers (2010) proposed that the unique contribution of vocabulary to reading comprehension may reflect a measurement artifact because "the current assessment tools for vocabulary are more accurate indices of the construct under study (oral language skills) than are assessment measures of listening comprehension, which are often largely dependent upon memory" (p. 204). We decreased the memory load in our listening comprehension task by providing pictures for the children for each answer choice and by reading the story twice. However, our single measure of vocabulary might not have been reliable enough to have strong effects over and above those of the listening-comprehension factor.

Finally, we examined whether classroom membership could be one source of variation in early reading fluency and comprehension. We found that in our data the effect of classroom membership was significant: $9 \%-12 \%$ of the variance in reading comprehension, $3 \%-8 \%$ of the variance in listening comprehension, and 7\%-9\% of the variance in reading fluency were attributable to being a member of a certain classroom. Thus, a portion of children's skills in reading and listening comprehension and reading fluency can be explained by the classroom effect (for similar findings, see Connor et al., 2011). This is true even in the Finnish school system, where all children are enrolled in public schools with a national curriculum that emphasizes similar literacy instruction (e.g., in Grade 1, there is systematic 
use of phonics with a strong focus on letter sound relations, and, from Grade 2 onward, there is a focus on skills for reading fluency and reading comprehension). The reasons for the classroom effects may relate to characteristics of classroom or teaching, but they may also be caused by nonrandom selection of children into classrooms. Identification of potential differences between the classrooms affecting children's reading development and motivation toward reading would require a finer analysis of the differences, such as classroom observations (Douglas, 2009; Lerkkanen et al., 2012; Pakarinen et al., 2014).

Some limitations of our study are worth mentioning. First, some of our measures suffered from low reliability and skewed distributions. Although we used an SEM approach with latent factors and a robust WLSMV estimator, having stronger and purer measures, particularly for listening comprehension and vocabulary, could have increased the strength of the model. Despite the problems with the language measures, they were the strongest predictors of reading comprehension. It is plausible that, had the measures been of higher quality, their effects may have been even stronger. Also, the use of different tests of listening comprehension in the two grades might have resulted in a different amount of explained variance, and that this difference in Grade 1 left more variance for reading fluency to explain. Second, including memory or inference-making measures in the study could have increased the explanatory power of the model. Working memory (e.g., Cain et al., 2004; Georgiou et al., 2009), inference-making skills (e.g., Cain et al., 2004), and comprehension monitoring (e.g., Cain et al., 2004; Kinnunen, Vauras, \& Niemi, 1998) can contribute to reading comprehension. Third, our sample did not include individual assessments of the SVR components in addition to group-based measures. However, based on our analyses on a subsample of the current sample where individual assessments were conducted, the correlations between the reading-fluency tasks we report here and reading tasks assessed individually (word-list reading, pseudoword-list reading, and text reading) were high (Pearson correlation coefficients were .59-.77, depending on the task and assessment time point). Finally, we also know that different reading-comprehension tasks require different skills (e.g., Keenan, Betjemann, \& Olson, 2008; Keenan \& Meenan, 2014). However, the reading-comprehension test we used belongs to the normative Finnish reading test battery for primary school and has been used frequently in a number of Finnish reading studies (e.g. Soodla et al., 2015; Torppa, Tolvanen, et al., 2007).

To conclude, the findings of this longitudinal study support the validity of the SVR model in Finnish-that is, reading fluency and listening 
comprehension had unique contributions to reading comprehension. The findings also suggest that their dynamic effects on the components in the model change over time. The direct contribution of reading fluency declined, but the contribution of listening comprehension increased. Although a similar declining relationship between word decoding and reading comprehension has been reported in opaque orthographies, we argue that, because in transparent orthographies a necessary level of decoding automaticity for comprehension is typically achieved by the end of Grade 1, the connection between word decoding/fluency and comprehension is short-lived.

\section{References}

Adlof, S. M., Catts, H., \& Little, T. D. (2006). Should the simple view of reading include a fluency component? Reading and Writing, 19, 933-958. doi:10.1007/ s11145-006-9024-Z

Ahtola, A., Silinskas, G., Poikonen, P. L., Kontoniemi, M., Niemi, P., \& Nurmi, J. E. (2011). Transition to formal schooling: Do transition practices matter for academic performance? Early Childhood Research Quarterly, 26, 295-302. doi:10.1016/j.ecresq.2010.12.002

Aro, M., \& Wimmer, H. (2003). Learning to read: English in comparison to six more regular orthographies. Applied Psycholinguistics, 24, 621-635. doi:10.1017/ S0142716403000316

Babayiğit, S., \& Stainthorp, R. (2011). Modeling the relationships between cognitive-linguistic skills and literacy skills: New insights from a transparent orthography. Journal of Educational Psychology, 103, 169-189. doi:10.1037/ a0021671

Betjemann, R. S., Willcutt, E. G., Olson, R. K., Keenan, J. M., DeFries, J. C., \& Wadsworth, S. J. (2008). Word reading and reading comprehension: Stability, overlap and independence. Reading and Writing, 21, 539-558. doi:10.1007/ s11145-007-9076-8

Cain, K., Oakhill, J., \& Bryant, P. (2004). Children's reading comprehension ability: Concurrent prediction by working memory, verbal ability, and component skills. Journal of Educational Psychology, 96, 31-42. doi:10.1037/0022-0663.96.1.31

Calet, N., Gutierrez-Palma, N., \& Defior, S. (2015). A cross-sectional study of fluency and reading comprehension in Spanish primary school children. Journal of Research in Reading, 38, 272-285. doi:10.1111/1467-9817.12019

Caravolas, M., Lervåg, A., Mousikou, P., Efrim, C., Litavsky, M., OnochieQuintanilla, E., ... Hulme, C. (2012). Common patterns of prediction of literacy development in different alphabetic orthographies. Psychological Science, 23, 678-686. doi:10.1177/0956797611434536. 
Catts, H. W., Adlof, S. M., \& Weismer, S. E. (2006). Language deficits in poor comprehenders: A case for the simple view of reading. Journal of Speech, Language, andHearingResearch,49,278-293.doi:10.1037/0708-5591.49.2.125

Catts, H. W., Hogan T., \& Adlof, S. M. (2005). Developmental changes in reading and reading disabilities. In W. H. Catts \& A. Kamhi (Eds.), Connections between language and reading disabilities (pp. 25-40). Mahwah, NJ: Erlbaum.

Connor, C. M., Morrison, F. J., Fishman, B., Giuliani, S., Luck, M., Underwood, P. S., . . S Schatschneider, C. (2011). Testing the impact of child characteristics $\times$ instruction interactions on third graders' reading comprehension by differentiating literacy instruction. Reading Research Quarterly, 46, 189-221. doi:10.1598/RRQ.46.3.1

de Jong, P. F., \& van der Leij, A. (2002). Effects of phonological abilities and linguistic comprehension on the development of reading. Scientific Studies of Reading, 6, 51-77. doi:10.1207/S1532799XSSR0601_03

Denckla, M. B., \& Rudel, R. G. (1976). Rapid "automatized” naming (R.A.N.): Dyslexia differentiated from other learning disabilities. Neuropsychologia, 14, 471-479. doi:10.1016/0028-3932(76)90075-0

Diakidoy, I. E. N., Stylianou, P., Karefillidou, C., \& Papageorgiou, P. (2005). The relationship between listening and reading comprehension of different types of text at increasing grade levels. Reading Psychology, 26, 55-80. doi:10.1080/02702710590910584

Douglas, K. (2009). Sharpening our focus in measuring classroom instruction. Educational Researcher, 38, 518-521. doi:10.3102/0013189X09350881

Dufva, M., Niemi, P., \& Voeten, M. (2001). The role of phonological memory, decoding, and comprehension skills in reading development: From preschool to grade 2. Reading and Writing, 14, 91-117. doi:10.1037/0022-0663.96.4.682

Dunn, L. M., \& Dunn, L. M. (1981). Peabody Picture Vocabulary Test-Revised. Circle Pines, MN: American Guidance Service.

Edmonds, M. S., Vaughn, S., Wexler, J., Reutebuch, C. K., Cable, A., Tackett, K. K., \& Schnakenberg, J. W. (2009). A synthesis of reading interventions and effects on reading outcomes for older struggling readers. Review of Educational Research, 79, 262-300. doi:10.3102/0034654308325998

Florit, E., \& Cain, K. (2011). The Simple View of Reading: Is it valid for different types of alphabetic orthographies? Educational Psychology Review, 23, 553-576. doi:10.1007/s10648-011-9175-6

Georgiou, G., Das, J. P., \& Hayward, D. (2009). Revisiting the "simple view of reading" in a group of children with poor reading comprehension. Journal of Learning Disabilities, 42, 76-84. doi:10.1177/0022219408326210

Georgiou, G., Parrila, R., \& Papadopoulos, T. (2008). Predictors of word decoding and reading fluency in English and Greek: A cross-linguistic comparison. Journal of Educational Psychology, 100, 566-580. doi:10.1037/0022-0663.100.3.566 
Gough, P. B., \& Tunmer, W. E. (1986). Decoding, reading, and reading disability. RASE: Remedial \& Special Education, 7, 6-10. doi:10.1177/ 074193258600700104

Harlaar, N., Cutting, L., Deater-Deckard, K., DeThorne, L. S., Justice, L. M., Schatschneider, C, . . P Petrill, S.A. (2010). Predicting individual differences in reading comprehension: A twin study. Annals of Dyslexia, 60, 265-288. doi:10.1007/s11881-010-0044-7

Holopainen, L., Ahonen, T., \& Lyytinen, H. (2001). Predicting delay in reading achievement in a highly transparent language. Journal of Learning Disabilities, 34, 401-413. doi:10.1177/002221940103400502

Hudson, R. F., Torgesen, J. K., Lane, H. B., \& Turner, S. J. (2012). Relations among reading skills and sub-skills and text-level reading proficiency in developing readers. Reading and Writing, 25, 483-507. doi:10.1007/s11145-010-9283-6

Joshi, R. M., Tao, S., Aaron, P. G., \& Quiroz, B. (2013). Cognitive componential model of reading applied to different orthographies. Journal of Learning Difficulties, 45, 480-486. doi:10.1177/0022219411432690

Keenan, J. M., Betjemann, R. S., \& Olson, R. K. (2008). Reading comprehension tests vary in the skills they assess: Differential dependence on decoding and oral comprehension. Scientific Studies of Reading, 12, 281-300. doi: $10.1080 / 10888430802132279$

Keenan, J. M., Betjemann, R., Wadsworth, S. J., DeFries, J. C., \& Olson, R. K. (2006). Genetic and environmental influences on reading and listening comprehension. Journal of Research in Reading, 29, 75-91. doi:10.1111/j.1467-9817.2006.00293.x

Keenan, J. M., \& Meenan, C. E. (2014). Test differences in diagnosing reading comprehension deficits. Journal of Learning Disabilities, 47, 125-135. doi:10.1177/0022219412439326

Kendeou, P., Papadopoulos, T. C., \& Kotzapoulou, M. (2013). Evidence for the early emergence of the simple view of reading in a transparent orthography. Reading and Writing, 26, 189-204. doi:10.1007/s11145-012-9361-z

Kendeou, P., Savage, R., \& van den Broek, P. (2009). Revisiting the simple view of reading. British Journal of Educational Psychology, 79, 353-370. doi:0.1348/978185408X369020

Kim, Y. S., Wagner, R. K., \& Foster, L. (2011). Relations among oral reading fluency, silent reading fluency, and reading comprehension: A latent variable study of first-grade readers. Scientific Studies of Reading, 15, 338-362. doi:1 0.1080/10888438.2010.493964

Kim, Y. S., Wagner, R. K., \& Lopez, D. (2012). Developmental relations between reading fluency and reading comprehension: A longitudinal study from Grade 1 to Grade 2. Journal of Experimental Psychology, 113, 93-111. doi:10.1016/j. jecp.2012.03.002 
Kinnunen, R., Vauras, M., \& Niemi, P. (1998). Comprehension monitoring in beginning readers. Scientific Studies in Reading, 2, 353-375. doi:10.1207/ s1532799xssr0204_4

Kirby, J., Parrila, R., \& Pfeiffer, S. (2003). Naming speed and phonological awareness as predictors of reading development. Journal of Educational Psychology, 95, 453-464. doi:10.1037/0022-0663.95.3.453

Kirby, J. R., \& Savage, R. S. (2008). Can the simple view deal with the complexities of reading? Literacy, 42, 75-82. doi:10.1111/j.1741-4369.2008.00487.x

Klauda, S. L., \& Guthrie, J. T. (2008). Relationships of three components of reading fluency to reading comprehension. Journal of Educational Psychology, 100, 310-321. doi:10.1037/0022-0663.100.2.310

Lepola, J., Poskiparta, E., Laakkonen, E., \& Niemi, P. (2005). Developmental interaction of phonological and motivational processes and naming speed in predicting word recognition in Grade 1. Scientific Studies of Reading, 9, 365-396. doi:10.1207/s1532799xssr0904_3

Lerkkanen, M.-K., Kiuru, N., Pakarinen, E., Viljaranta, J., Poikkeus, A. M., RaskuPuttonen, H., . . . Nurmi, J. E. (2012). The role of teaching practices in the development of children's interest in reading and mathematics in kindergarten. Contemporary Educational Psychology, 37, 266-279. doi:10.1016/j. cedpsych.2011.03.004

Lerkkanen, M.-K., Niemi, P., Poikkeus, A.-M., Poskiparta, M., Siekkinen, M., \& Nurmi, J.-E. (2006). The ongoing First Steps study [Alkuportaat]. Jyväskylä, Finland: Universities of Jyväskylä, Joensuu, and Turku. See https://www.jyu.fi/ ytk/laitokset/psykologia/en/research/research-areas/motivation-and-learning/ projects/first-steps

Lerkkanen, M.-K., Poikkeus, A.-M., \& Ketonen, R. (2006). ARMI—Luku-ja kirjoitustaidon arviointi-materiaali 1. luokalle [ARMI-A tool for assessing reading and writing skills in Grade 1]. Helsinki: WSOY.

Lerkkanen, M. K., Rasku-Puttonen, H., Aunola, K., \& Nurmi, J. E. (2004). Predicting reading performance during the first and the second year of primary school. British Educational Research Journal, 30, 67-92. doi:10.1080/ 01411920310001629974

Lerkkanen, M. K., Rasku-Puttonen, H., Aunola, K., \& Nurmi, J. E. (2005). Mathematical performance predicts progress in reading comprehension among 7-year olds. European Journal of Psychology of Education, 20, 121-137. doi:10.1007/BF03173503

Lindeman, J. (2000). Ala-asteen lukutesti: Käyttäjän käsikirja [The comprehensive school reading test]. Turku, Finland: Oppimistutkimuksen keskus, Turun yliopisto [Center for Learning Research, Turku University].

Lonigan, C. J., Burgess, S. R., \& Anthony, J. L. (2000). Development of emergent literacy and early reading skills in preschool children: Evidence from a 
latent-variable longitudinal study. Developmental Psychology, 36, 596-613. doi:10.1037/0012-1649.36.5.596

Lyytinen, H., Aro, M., Eklund, K., Erskine, J., Guttorm, T., Laakso, M., . . Torppa, M. (2004). The development of children at familial risk for dyslexia: Birth to early school age. Annals of Dyslexia, 54, 184-220. doi:10.1002/dys.274

Manolitsis, G., Georgiou, G., \& Parrila, R. (2011). Revisiting the home literacy model of reading development in an orthographically consistent language. Learning and Instruction, 21, 496-505. doi:10.1016/j.learninstruc.2010.06.005

Megherbi, H., Seigneuric, A., \& Ehrlich, M. F. (2006). Reading comprehension in French 1st and 2nd grade children: Contribution of decoding and language comprehension. European Journal of Psychology of Education, 21, 135-147. doi:10.1007/BF03173573

Müller, K., \& Brady, S. (2001). Correlates of early reading performance in a transparent orthography. Reading and Writing, 14, 757-799. doi:10.1023/A: 1012217704834

Muter, V., Hulme, C., Snowling, M. J., \& Stevenson, J. (2004). Phonemes, rimes, vocabulary, and grammatical skills as foundations of early reading development: Evidence from a longitudinal study. Developmental Psychology, 40, 665-681. doi:10.1037/0012-1649.40.5.665

Muthén, L. K. M., \& Muthén, B. O. (1998-2009). Mplus user's guide. Los Angeles: Muthén \& Muthén.

Nation, K., Clarke, P., Marshall, C. M., \& Durand, M. (2004). Hidden language impairments in children: Parallels between poor reading comprehension and specific language impairment? Journal of Speech, Language, and Hearing Research, 47, 199-211. doi:10.1044/1092-4388(2004/017

Olson, R. K., Keenan, J. M., Byrne, B., Samuelsson, S., Coventry, W. L., Corley, R., . . Hulslander, J. (2011). Genetic and environmental influences on vocabulary and reading development. Scientific Studies of Reading, 15, 26-46. doi: $10.1080 / 10888438.2011 .536128$

Ouellette, G. P. (2006). What's meaning got to do with it: The role of vocabulary in word reading and reading comprehension. Journal of Educational Psychology, 98, 554-566. doi:10.1037/0022-0663.98.3.554

Ouellette, G., \& Beers, A. (2010). A not-so-simple view of reading: How oral vocabulary and visual-word recognition complicate the story. Reading and Writing, 23, 189-208. doi:10.1007/s11145-008-9159-1

Pakarinen, E., Aunola, K., Kiuru, N., Lerkkanen, M.-K., Poikkeus, A.-M., Siekkinen, M., \& Nurmi, J.-E. (2014). The cross-lagged associations between classroom interactions and children's achievement behaviors. Contemporary Educational Psychology, 39, 248-261. doi:10.1016/j. cedpsych.2014.06.001

Perfetti, C. A. (1985). Reading ability. New York: Oxford University Press. 
Protopapas, A., Simos, P. G., Sideridis, G. D., \& Mouzaki, A. (2012). The components of the simple view of reading: A confirmatory factor analysis. Reading Psychology, 33, 217-233. doi:10.1080/02702711.2010.507626

Puolakanaho, A., Ahonen, T., Aro, M., Eklund, K., Leppänen, P. H. T., Poikkeus, A. M., . . . Lyytinen, H. (2007). Very early phonological and language skills: Estimating individual risk of reading disability. Journal of Child Psychology and Psychiatry, 48, 923-931. doi:10.1111/j.1469-7610.2007.01763.x

Ricketts, J., Nation, K., \& Bishop, D. V. M. (2007). Vocabulary is important for some, but not all reading skills. Scientific Studies of Reading, 11, 235-257. doi:10.1080/10888430701344306

Roch, M., \& Levorato, M. C. (2009). Simple view of reading in Down syndrome: The role of listening comprehension and reading skills. International Journal of Language \& Communication Disorders, 2, 206-223. doi:10.1080/13682820802012061

Savage, R. S., \& Frederickson, N. (2005). Evidence of a highly specific relationship between rapid automatic naming of digits and text reading speed. Brain and Language, 93, 152-159. doi:10.1016/j.bandl.2004.09.005

Schatschneider, C., Fletcher, J. M., Francis, D. J., Carlson, C. D., \& Foorman, B. R. (2004). Kindergarten prediction of reading skills: A longitudinal comparative analysis. Journal of Educational Psychology, 96, 265-282. doi:10.1037/0022-0663.96.2.265

Sénéchal, M. (2006). Testing the Home Literacy Model: Parent involvement in kindergarten is differentially related to Grade 4 reading comprehension, fluency, spelling, and reading for pleasure. Journal for the Scientific Study of Reading, 10, 59-87. doi:10.1207/s1532799xssr1001_4

Seymour, P. H. K., Aro, M., \& Erskine, J. M. (2003). Foundation literacy acquisition in European orthographies. British Journal of Psychology, 94, 143-174. doi:10.1348/000712603321661859

Silverman, R., Speece, D. L., Harring, J. R., \& Ritchey, K. (2013). Fluency has a role in the Simple View of Reading. Scientific Studies of Reading, 17, 108-133. doi:10.1080/10888438.2011.618153

Soodla, P., Lerkkanen, M.-K., Niemi, P., Kikas, E., Silinskas, G., \& Nurmi, J.E. (2015). Does early reading instruction promote the rate of acquisition? A comparison of two transparent orthographies. Learning and Instruction, 38, 14-23. doi:10.1016/j.learninstruc.2015.02.002

Statistics Finland. (2007). Statistical databases. Retrieved April 5, 2012, from www.stat.fi/tup/tilastotietokannat/index_en.html

Stothard, S. E., \& Hulme, C. (1995). A comparison of phonological skills in children with reading comprehension difficulties and children with decoding difficulties. Journal of Child Psychology and Psychiatry, 36, 399-408. doi:10.1111/j.1469-610.1995.tb01298.x 
Stuart, M., Stainthorp, R., \& Snowling, M. (2008). Literacy as a complex activity: Deconstructing the simple view of reading. Literacy, 42, 59-66. doi:10.1111/j.1741-4369.2008.00490.x

Torppa, M., Georgiou, G., Salmi, P., Eklund, K., \& Lyytinen, H. (2012). Examining the double-deficit hypothesis in an orthographically consistent language. Scientific Studies of Reading, 16, 287-315. doi:10.1080/10888438.2011.554470

Torppa, M., Parrila, R., Niemi, P., Poikkeus, A.-M., Lerkkanen, M.-K., \& Nurmi, J.-E. (2013). The double deficit hypothesis in the transparent Finnish orthography: A longitudinal study from kindergarten to Grade 2. Reading and Writing, 26, 1353-1380. doi:10.1007/s11145-012-9423-2

Torppa, M., Poikkeus, A. M., Laakso, M. L., Leskinen, E., Tolvanen, A., Leppänen, P. H. T., . . Lyytinen, H. (2007). Modeling the early paths of phonological awareness and factors supporting its development in children with and without familial risk for dyslexia. Scientific Studies of Reading, 11, 73-103. doi:10.1080/10888430709336554

Torppa, M., Tolvanen, A., Poikkeus, A.-M., Eklund, K., Lerkkanen, M.-K., Leskinen, E., \& Lyytinen, H. (2007). Reading development subtypes and their early characteristics. Annals of Dyslexia, 57, 3-32. doi:10.1007/ s11881-007-0003-0

Verhoeven, L., \& van Leeuwe, J. (2008). Prediction of the development of reading comprehension: A longitudinal study. Applied Cognitive Psychology, 22, 407-423. doi:10.1002/acp.1414

Vilenius-Tuohimaa, P., Aunola, K., \& Nurmi, J. E. (2008). The association between mathematical word problems and reading comprehension. Educational Psychology, 28, 409-426. doi:10.1080/014434107017082 